\title{
RUSSELL AND GÖDEL
}

\author{
ALASDAIR URQUHART
}

\begin{abstract}
This paper surveys the interactions between Russell and Gödel, both personal and intellectual. After a description of Russell's influence on Gödel, it concludes with a discussion of Russell's reaction to the incompleteness theorems.
\end{abstract}

§1. Gödel's personal interactions with Russell. Although Russell and Gödel met on only a few occasions, they may have encountered each other as early as 1940. In his book Beyond, the literary critic I.A. Richards wrote:

Logicians, it is observable, from Aristotle on, have been signally unable, for one another and for the laity, to say what Logic is. As Bertrand Russell delightedly pointed out - to Tarski, Carnap, Willard Van Quine, Gödel, and a few others who had met to decide just this - they deserve to be sacked for not knowing what they are doing $[19$, p. 16].

Richards added a footnote to this passage: "In 1940, in 9 Kirkland Place, Cambridge, Mass., at the end of a day spent in fruitlessly discussing that problem." Quine reports in his autobiography that in the fall term of 1940 there were periodic gatherings of logicians at Harvard such as Richards describes:

Russell, Carnap, and Tarski were all at hand ... Russell was giving the William James Lectures, backed by a seminar. The lectures became An Inquiry into Meaning and Truth. There was an effort, issuing from Brown University, to promote periodic gatherings for discussion. Huntington, Lewis, Sheffer, Prall, and Ivor Richards were among the Harvard participants, and the Brown contingent included Baylis, A.A. Bennett, and Ducasse. Our three-star cast managed to bow out after two of these unwieldy sessions, and to meet in the seclusion rather of Ivor's study or Carnap's flat along with a few of us younger devotees [18, pp. 149-150].

Received September 8, 2016.

2010 Mathematics Subject Classification. 01A60, 03-03.

Key words and phrases. Bertrand Russell, Kurt Gödel, Principia Mathematica, incompleteness theorem. 
Richards's study was in 9 Kirkland Place, consistent with Quine's description. Quine does not mention Gödel, but the latter gave a lecture on the consistency of the continuum hypothesis at Brown University on November 15 1940, so his presence in Harvard around that time is plausible, though there does not seem to be an independent record of it.

In the last months of 1943, Russell was living in Princeton, where he lectured on 'Postulates of Scientific Inference.' There, he engaged in philosophical discussion with Gödel:

While in Princeton, I came to know Einstein fairly well. I used to go to his house once a week to discuss with him and Gödel and Pauli. These discussions were in some ways disappointing, for, although all three of them were Jews and exiles and, in intention, cosmopolitans, I found that they all had a German bias towards metaphysics, and in spite of our utmost endeavours we never arrived at common premisses from which to argue. Gödel turned out to be an unadulterated Platonist, and apparently believed that an eternal "not" was laid up in heaven, where virtuous logicians might hope to meet it hereafter [31, p. 341].

Russell's last sentence echoes an earlier remark in the second edition of The Principles of Mathematics: "... not even the most ardent Platonist would suppose that the perfect "or" is laid up in heaven, and that the "or's" here on earth are imperfect copies of the celestial archetype" [25, p. ix].

In September 1971, Kenneth Blackwell, the archivist of the Bertrand Russell archives at McMaster University in Ontario, called Gödel's attention to this passage of Russell's autobiography. In an unsent rough draft of a reply to Blackwell's letter, Gödel wrote:

I have to say first (for the sake of truth) that I am not a Jew (even though I don't think this question is of any importance.) 2.) that the passage gives the wrong impression that I had many discussions with Russell, which was by no means the case (I remember only one). 3.) Concerning my "unadulterated" Platonism it is no more "unadulterated" than Russell's own in 1921 when in the Introduction to Mathematical Philosophy he said: "...." At that time evidently Russell had met the "not" even in this world but later on under the influence of Wittgenstein he chose to overlook it [12, pp. 316-317].

Gödel did not fill in the quotation from Russell in his rough draft, but it is very likely that he had in mind the sentence "Logic is concerned with the real world just as truly as zoology, though with its more abstract and general features" [23, p. 169], a passage that he quoted in his contribution to the Schilpp volume [37, p. 127]; Hao Wang later observed that "the sentence quoted by Gödel is his favorite and corresponds pretty closely to his own view" [41, p. 112].

§2. Gödel's intellectual interactions with Russell. In the 1920s, the three massive volumes of Principia Mathematica, though increasingly outdated, still loomed large in the landscape of logic. The cutting edge of research had 
moved to Poland and Germany, but Whitehead and Russell's treatise still remained a basic reference in the field.

Gödel's attitude to Principia Mathematica was rather critical. He ordered and received a personal copy of the book in July 1928 [4, p. 275], remarking in a letter of 24 September to Herbert Feigl:

I would like to have heard how else you spent your summer. ... I myself was in Brno the whole time and among other things read a part of Principia mathematica, about which, however, I was less enthusiastic than I had expected from its reputation [12, p. 403].

In his famous essay on Russell's logic, he remarked:

It is to be regretted that this first comprehensive and thorough going presentation of a mathematical logic and the derivation of Mathematics from it is so greatly lacking in formal precision in the foundations (contained in $* \mathbf{1}-* \mathbf{2 1}$ of Principia), that it presents in this respect a considerable step backwards as compared with Frege [8, p. 126].

2.1. Russell's influence on Gödel. In spite of the highly critical remarks quoted above, Gödel's work shows the strong imprint of Principia from his work on completeness to the results on the continuum hypothesis. Gödel proved completeness for a version of the quantification theory of Principia Mathematica, and the title of his great incompleteness paper of 1931 [7] includes the name of Whitehead and Russell's treatise; the incompleteness theorem is proved for a rigorously formulated version of the simple theory of types, with the natural numbers as ground type.

The best known example of Russell's influence on Gödel is the latter's work on constructible sets, inspired originally by the ramified type hierarchy. Gödel alludes to this inspiration in his contribution to the Schilpp volume:

The theory of orders proves more fruitful if considered from a purely mathematical standpoint, independently of the philosophical question whether impredicative definitions are admissible. Viewed in this manner, i.e., as a theory built up within the framework of ordinary mathematics, where impredicative definitions are admitted, there is no objection to extending it to arbitrarily high transfinite orders. ... Admitting transfinite orders, an axiom of reducibility can be proved. ... In addition this transfinite theorem of reducibility permits the proof of the consistency of the Axiom of Choice, of Cantor's Continuum-Hypothesis and even of the generalized ContinuumHypothesis ... with the axioms of set theory as well as of Principia [8, pp. 146-147].

Strikingly, Gödel not only describes his work on constructible sets as a mathematical generalization of the ramified type hierarchy, but also depicts a key lemma in his consistency proof as a kind of generalized axiom of reducibility.

In the universe of constructible sets, every subset of the integers appears in the constructible hierarchy at the level of a countable ordinal, so that the 
continuum hypothesis holds for the constructible sets. This result Gödel names "the fundamental theorem" and claims (in a lecture given at Göttingen in 1939) to have been inspired by the axiom of reducibility:

I should also like to mention that the fundamental theorem constitutes the corrected core of the so-called Russellian axiom of reducibility. After all, as was mentioned a while ago, Russell had previously given a construction similar to that of the $M_{\alpha}$, but had restricted himself to finite orders. His axiom of reducibility then says that the orders of the sets of every type are bounded by a fixed finite number. $\mathrm{He}$ was evidently far from being able to prove that. But it now turns out that if the construction of the orders is continued into the transfinite, the existence of certain transfinite bounds actually becomes provable. That is the content of the fundamental theorem [11, pp. 143-145].

The influence of the ramified type hierarchy on the genesis of the theory of constructible sets is well known. A lesser known connection between the work of Russell and Gödel is the link between Principia Mathematica and the Dialectica interpretation.

In his essay on Russell's logic, Gödel made a somewhat enigmatic remark:

In the first edition of Principia, where it was a question of actually building up logic and mathematics, the constructivistic attitude was, for the most part, abandoned ... What is left of the constructive attitude is only: (1.) The introduction of classes as a façon de parler; (2.) the definition of $\sim, \vee, \cdot$, etc., as applied to propositions containing quantifiers (which incidentally proved its fecundity in a consistency proof for arithmetic); ... [37, p. 143].

Burton Dreben queried Gödel about this passage in a letter of December 30 1969 [12, p. 393], but received no reply. The answer to Dreben's query finally emerged in a manuscript in the Nachlaß. At the end of his notes for his 1941 lectures at Princeton on his functional interpretation of arithmetic, subsequently known as the Dialectica interpretation, Gödel elucidates the connection with the work of Whitehead and Russell:

Finally, I wish to remark that this whole scheme of defining the logical notions has a certain relationship to what Russell intended in the Section 9 of the Principia Mathematica. Namely it is chiefly the question of defining the meaning of the logical operations for expressions involving quantifiers provided that their meaning for no-quantifier expressions is given [12, p. 391].

It is well known that Jacques Herbrand found inspiration in one of the oddest and most idiosyncratic passages in $P M$, namely $* \mathbf{9}$. Principia Mathematica contains not one, but two, foundations for the theory of quantification. It is the first, nonstandard foundation given in $* \mathbf{9}$ that inspired Herbrand, though it is the later foundation in $* \mathbf{1 0}$ that forms the basis for the remainder of the work, and indeed, was the approach followed by almost all later logicians. I have discussed this connection with the work of Herbrand 
in my contribution to a collection celebrating the 100th anniversary of the publication of Principia Mathematica [39].

Why did Russell ${ }^{1}$ give two versions of quantification theory? The problem that led to this apparently puzzling procedure arises from the theory of types. In Principia Mathematica, $* \mathbf{1}$ to $* \mathbf{5}$ are devoted to a development of the propositional calculus. However, the variables $p, q, r \ldots$ in these numbers are understood to range over elementary propositions. When in $* \mathbf{9}$, two new primitive ideas are introduced, universal and existential quantification, the problem arises of extending the propositional connectives to this new realm of propositions. Russell remarks

In virtue of the fact that disjunction and negation do not have the same meanings as applied to elementary or to first-order propositions, it follows that, in asserting the primitive propositions of $* \mathbf{1}$, we must either confine them, in their application, to propositions of a single type, or we must regard them as the simultaneous assertion of a number of different primitive propositions, corresponding to the different meanings of "disjunction" and "negation" [43, p. 127-128].

The aim of $* \mathbf{9}$ is to overcome this problem by defining disjunction and negation for quantified propositions, assuming that they have already been defined for elementary propositions. The definitions, given in $* \mathbf{9 . 0 1}$ to $* \mathbf{9 . 0 8}$, use the familiar rules for converting a proposition to prenex normal form. Having defined the connectives by this technique, however, Russell is now faced with a further difficulty, namely that of proving the first-order versions of the primitive propositions of the propositional calculus. In order to do this, he introduces two new primitive propositions.

$$
\begin{array}{rrr}
* 9.1 & \vdash: \phi x . \supset .(\exists z) . \phi z \quad P p \\
* 9.11 & \vdash: \phi x \vee \phi y . \supset .(\exists z) . \phi z & P p
\end{array}
$$

With this addition, Russell is able to prove all of the axioms and rules of the propositional calculus. The most difficult axiom to prove is

$$
\text { *1.2 } \quad-: p \vee p . \supset . p . \quad P p .
$$

In fact, it is exactly for the purpose of proving the first-order version of this primitive proposition that Russell is forced to introduce $* \mathbf{9 . 1 1}$. A further connection with Gödel's Dialectica interpretation appears here, since the contraction axiom $p \vee p . \supset . p$ is the most difficult axiom of the propositional calculus to verify in this interpretation. (In Gödel's case, where the context is the intuitionistic propositional calculus, the contraction axiom takes the form $p \supset(p \wedge p)$-however, this is interdeducible with the Russellian form in the context of classical logic.)

With the developments of $* \mathbf{9}$ completed, Principia Mathematica proceeds in $* \mathbf{1 0}$ with a more conventional axiomatic development of quantification theory, described as an "alternative method," referring to the preceding $* \mathbf{9}$

\footnotetext{
${ }^{1}$ It seems safe to attribute $* \mathbf{9}$ to Russell alone, since it exhibits Russell's typical philosophical scruples.
} 
only to justify the use of propositional connectives as applied to quantified propositions, as well as the primitive propositions required for the alternative method.

The interesting but slightly odd developments in $* \mathbf{9}$ are often overlooked in discussions of Principia Mathematica. Yet, as we have seen, they suggested new ideas to both Gödel and Herbrand. In the work of these later logicians, however, the developments of $* \mathbf{9}$, inspired by philosophical scruples, are transformed into technical tools for studying the consistency problem (in Gödel's case) and investigating the Entscheidungsproblem (in Herbrand's case).

We have seen that Gödel acknowledged a debt to Russell in two different cases. However, it should be emphasized that Gödel's work involves major transformations in both cases. The work of Russell is greatly lacking in clarity and rigour, as opposed to the precise versions given by Gödel. Robert Solovay points out in his introductory notes to two lectures by Gödel on his consistency proof, that in Principia Mathematica, "one does not find the sort of mathematically precise ramified hierarchy that Gödel describes and attributes to Russell," concluding that "Gödel's well-known comments ... to the effect that his notion of constructibility may be regarded as a natural extension of Russell's ramified hierarchy into the transfinite now strikes this writer as much too generous" [11, pp. 119-120].

2.2. Substitutional theories of classes. Above, we described two cases where Russell's work had a direct influence on that of Gödel. In the present subsection, we discuss research of Russell that shows a striking parallelism with Gödel's construction of undecidable propositions. In this case, though, direct influence is ruled out, because Russell's investigations have only recently been published in Volume 5 of the Collected Papers [36].

Russell's famous paper On Denoting [21] expounding his theory of descriptions, is now mainly of interest to philosophers - it is usually interpreted as a contribution to the analysis of the meaning of propositions in ordinary language. However, as I argued in an earlier paper [38], when Russell first conceived it, he saw it mainly as a contribution to logic. Its importance to him in 1905 was that it seemed to give him a way forward in the project in which he was engaged at that time - the struggle to provide consistent foundations for logic, overcoming the paradoxes that had bedevilled him since he came across them in the spring of 1901.

The device of contextual definition provided by the theory of descriptions aroused Russell's hopes that he could overcome the paradoxes by simplifying his ontology. The result was the substitutional theory of 1905 and 1906 (more correctly, "substitutional theories," since he continually reworked his ideas during that time). The theory has a very simple primitive basis. In addition to the usual apparatus of connectives and quantifiers, the only primitive symbol is a four-place relation, written by Russell as $p(b / a) ! q$, or $p / a ; b ! q$, and read as " $q$ is the result of substituting $b$ for $a$ in $p$."

The basic idea of the substitutional theory is that classes, relations, and propositional functions should not be quantified over (i.e., considered as 
terms), but should be eliminated in favour of the notion of a matrix consisting of a proposition and a constituent of the proposition. For example the pair consisting of the proposition " 3 is a prime number" and the number 3 can stand for the set of prime numbers. The proposition does not have to be true; the designated constituent ( 3 in this case) simply plays the role of a dummy or place holder. The membership relationship can be defined by substitution; an object $b$ is a member of the class represented by the pair $p$, $a$ if the result of substituting $b$ for $a$ in $p$ is a true proposition.

Russell's conception of a proposition at this time is that it is a structured entity, having a form similar to that of a formula of first-order logic, except that it can contain other entities (physical objects, for example) in the place of constants. In a letter of 12 December 1904 to Frege, Russell said:

I believe that in spite of all its snowfields Mont Blanc itself is a component part of what is actually asserted in the proposition 'Mont Blanc is more than 4000 metres high'. We do not assert the thought, for this is a private psychological matter: we assert the object of the thought, and this is, to my mind, a certain complex (an objective proposition, one might say) in which Mont Blanc is itself a component part. If we do not admit this, then we get the conclusion that we know nothing at all about Mont Blanc [6, p. 169].

The notion of substitution that is part of Russell's theory of 1905 to 1906 is that of substituting one entity for another. For example, if Patricia is Russell's third wife, and Edith the fourth, then Patricia(Edith/Patricia) = Edith. A detailed development of this concept of structured proposition can be found in an article by Alonzo Church [2], and in my paper with Judy Pelham [17].

As some examples of propositions in the substitutional theory, here is a list of some primitive propositions, or axioms, listed by Russell in one of the earliest manuscripts [36] developing the substitutional theory:

1. $p \frac{x}{p} ! x$,

2. $p \frac{x}{x} ! p$,

3. $p \frac{x}{a} ! q \cdot p \frac{x}{a} ! r . \supset \cdot q=r$,

4. $r$ in $p . p$ in $q$. $\supset$. $r$ in $q$,

5. $p$ in $q . q$ in $p$. $\supset . p=q$,

6. $a \neq \sim p . p \frac{x}{a} ! q . \supset .(\sim p) \frac{x}{a} !(\sim q)$.

Here, the notation $p$ in $q$ should be read as " $p$ is a constituent of $q$," while $p=q$ stands for identity, where proposition $p$ and $q$ are identical if one can be obtained from the other by interchange of bound variables $[2,17]$. In Russell's substitutional theories, these are in fact defined notions, but here we treat them as primitive, to simplify matters.

Russell's original substitutional theory was type-free, with a single type of entities, including both physical and logical objects. This was a matter of some importance to Russell, since he wanted the axiom of infinity to be a logical truth. In his reply to Poincaré [22] published in September 1906 , he proves the axiom of infinity in his paper by constructing an infinite 
series of propositions. In the English original of his reply, he describes the construction as follows. Starting from two distinct entities $a$ and $u$, he continues:

By taking propositions into account, we can manufacture $\aleph_{0}$ entities.

E.g., put

$$
p_{0} \cdot=. a=u, \quad p_{n+1} \cdot=\cdot p_{n}=u ;
$$

it is not hard to prove that the successive $p$ 's are all different, and that there are therefore at least $\aleph_{0}$ entities. Hence the cardinals up to and including $\aleph_{0}$ exist, and the ordinals finite and of the second class exist [34, p. 203].

Unfortunately, the lack of type distinctions enables us to prove not only the axiom of infinity, but also contradictions. A paradox emerged that, as Russell put it in a letter to his friend the mathematician Ralph Hawtrey, "pilled the substitution theory" 2 [36, p. 125]. This paradox, as explained in the letter to Hawtrey, is as follows. Define a proposition $p_{0}$ by

$$
p_{0}=(\exists p, a)\left[a_{0}=p \frac{b}{a} ! q \wedge \neg p \frac{a_{0}}{a}\right],
$$

where we assume that $a_{0}$ and $b$ are objects that are not logically complex (they might be physically complex). Now define the proposition $R$ by

$$
R=p_{0} \frac{p_{0} \frac{b}{a_{0}} ! q}{a_{0}}
$$

The proposition $\neg R$ is equivalent to

$$
(p, a)\left[\left(p_{0} \frac{b}{a_{0}} ! q=p \frac{b}{a} ! q\right) \supset p \frac{p_{0} \frac{b}{a_{0}} ! q}{a}\right] .
$$

Hence, if we assume $\neg R$, then by substituting $p_{0}$ for $p$ and $a_{0}$ for $a$, we have

$$
p_{0} \frac{p_{0} \frac{b}{a_{0}} ! q}{a_{0}}
$$

that is to say,

$$
(\exists p, a)\left[p_{0} \frac{b}{a_{0}} ! q=p \frac{b}{a} ! q \wedge \neg p \frac{p_{0} \frac{b}{a_{0}} ! q}{a}\right] .
$$

However, from the identity $p_{0} \frac{b}{a_{0}} ! q=p \frac{b}{a} ! q$ and our basic assumptions about meaning of identity between structured propositions, we can conclude that $p=p_{0}$ and $a=a_{0}$, hence

$$
\neg\left(p_{0} \frac{p_{0} \frac{b}{a_{0}} ! q}{a_{0}}\right),
$$

showing that $R$ is a proposition that is equivalent to its own negation. Russell remarked to Hawtrey that in trying to avoid this paradox, he modified the substitution theory in various ways, but the paradox always reappeared in

\footnotetext{
${ }^{2}$ The Edwardian colloquialism "pilled" has the meaning of "failed in an examination"- - see the discussion in [36, p. 796].
} 
more and more complicated forms. To avoid it, Russell was forced to adopt the ramified theory of types.

The tricky substitution that produces Russell's substitutional paradox bears a striking resemblance to the substitution in Gödel's undecidable proposition. In fact, this is not a coincidence, because Gödel was engaged in a project that had a close resemblance to Russell's. In the summer of 1930, Gödel began to study the problem of proving the consistency of analysis. According to the notes on his work published posthumously by Hao Wang,

The problem he set for himself at that time was the relative consistency of analysis to number theory; ... He represented real numbers by formulas (or sentences) of number theory and found he had to use the concept of truth for sentences in number theory in order to verify the comprehension axiom for analysis. He quickly ran into the paradoxes (in particular, the Liar and Richard's) connected with truth and definability. He realized that truth in number theory cannot be defined in number theory and therefore his plan of proving the relative consistency of analysis did not work. He went on to draw the conclusion that in suitably strong systems such as that of Principia Mathematica (type theory) and that of set theory ('Zermelo-Fraenkel') there are undecidable propositions [40, p. 654] [41, p. 42].

Thus the resemblance between Russell's construction and Gödel's arises from the fact that they were both trying to give substitutional accounts of sets-replacing talk of sets by talk about the propositional functions that define them.

2.3. Contrasts between Russell and Gödel. We have just seen three cases where the work of Russell parallels that of Gödel, the first two where Gödel acknowledged a direct influence, the third where there was no direct influence, but a striking parallelism in the work of the two logicians.

Nevertheless, there are great contrasts between their work. The most striking difference is the lack of rigour in the work of Russell, and the corresponding exactness and precision in that of Gödel. We have already seen how Solovay contrasted Russell's work on the ramified theory of types and Gödel's groundbreaking work on the hierarchy of constructible sets. The presentation of the ramified theory of types in Principia Mathematica is so vague and unclear that historians of logic continue to argue about the correct interpretation of the theory; no such unclarity is possible in the work of Gödel.

Principia Mathematica is very far removed from a modern presentation of a formal system. The syntax is never precisely described, and the axioms and rules of inference are presented in a way that mixes together the syntax with its intended meaning. The formalism appears to be inextricably tied to its informal interpretation. As we shall see in the last section, it is this last feature of Russell's logic that seems to have led to some misunderstandings on his part. 
§3. Russell's response to Gödel's theorem. Bertrand Russell left logic after the publication of the third volume of Principia Mathematica in 1913 [42]. In 1948, speaking of his collaboration with Whitehead, he wrote:

Neither of us alone could have written the book; even together, and with the alleviation brought about by mutual discussion, the effort was so severe that at the end we both turned aside from mathematical logic with a kind of nausea [28, p. 138].

Russell's only subsequent publications in logic are his introduction to the second edition of Principia [43] and a late paper discussing the construction of instants in time [24] using Whitehead's method of extensive abstraction; this last article arose from his work in the philosophy of physics.

Although as we saw above in Section 2.2, Russell anticipated some of the basic construction of Gödel's undecidable sentence, it remains a puzzling question as to whether he ever fully understood the incompleteness theorem. The evidence is sparse and hard to interpret.

Russell was aware of the incompleteness results shortly after their appearance. There is an offprint of the 1931 incompleteness paper [7] in the Russell Archives at McMaster University, but it bears an inscription showing that it originally belonged to Countess Amethe von Zeppelin, the translator of Carnap's Logical Syntax of Language; it has no significant marginalia. There is a second offprint in the Archives, found in Dora Russell's house after her death; disappointingly, it has no inscriptions or marginalia. However, we know that he learned of the result soon after its publication from a letter of Max Newman, also to be found in the Russell archives in Hamilton. In this letter, dated September 27 1966, Newman asks for Russell's support in proposing Gödel as a fellow of the Royal Society; in a handwritten footnote to the letter he adds: "I remember talking to you about Gödel's proof soon after it appeared."

There is a clear description of Gödel's numerical encoding of logical syntax in Russell's 1940 monograph on the philosophy of language, An Inquiry into Meaning and Truth [26, pp. 87-88], but the context of the discussion is not the incompleteness theorems; rather, Russell is concerned with the problem of describing a statement without making it.

Paul Arthur Schilpp, on Russell's prompting [13, p. 217], invited Gödel in a letter of November 18 1942, to contribute an essay to the Russell volume [37] in the Library of Living Philosophers. Gödel was a difficult author for editors; nevertheless, Schilpp, by a mixture of flattery and firm persuasion, did eventually succeed in obtaining a contribution from Gödel to the volume he was editing. Gödel sent a handwritten manuscript of his contribution to Schilpp on May 18 1943, but although Schilpp warned him that Russell had already started drafting his replies to criticisms in July, Gödel delayed submitting the corrected typescript of his article until September 27, in spite of Schilpp's increasingly urgent messages.

Russell by that time had completed his replies to the other contributors, and was busy with other projects. He was working hard to complete his History of Western Philosophy, preparing a set of lectures at Bryn Mawr, and in addition was getting ready to leave for England (although he did not 
return there until June 1944). Consequently, he told Schilpp in a letter of August 8: "I think I will say nothing about Gödel except a postscript that it came too late. In any case it is not likely to be controversial" [13, p. 229].

Gödel's only known letter to Russell is a short note [13, pp. 207-208] of September 281943 in which Gödel urged Russell to change his mind about not replying, emphasizing the fact that his article was in fact controversial. However, he did not succeed in altering Russell's decision, and the note planned by Russell is the only response to be found in the volume:

Dr. Gödel's most interesting paper on my mathematical logic came into my hands after my replies had been completed, and at a time when I had no leisure to work on it. As it is now about eighteen years since I last worked on mathematical logic, it would have taken me a long time to form a critical estimate of Dr. Gödel's opinions. His great ability, as shown in his previous work, makes me think it highly probable that many of his criticisms of me are justified. The writing of Principia Mathematica was completed thirty-three years ago, and obviously, in view of subsequent advances in the subject, it needs amending in various ways. If I had the leisure, I should be glad to attempt a revision of its introductory portions, but external circumstances make this impossible. I must therefore ask the reader to give Dr. Gödel's work the attention that it deserves, and to form his own critical judgment on it [37, p. 741].

There is no reason to disbelieve Russell's reasons for not providing an extended commentary on Gödel's article, even though he had written long and detailed comments on the other articles in the Schilpp volume. In a response to Gödel's letter of September 28, he wrote Schilpp in a letter of October 5, in which he said:

I have received Gödel's article, and a letter from him, urging me to answer it. It is quite impossible for me to make a detailed answer. I have not worked at mathematical logic since 1927 and it would take me at least a month's work. I am prepared to write a short paragraph saying I am unable to form a critical estimate of his article, but I think it quite probable that most of his criticisms are justified. I hope this will satisfy him and you [13, p. 231].

It is very unfortunate that Gödel's famous article [8] did not elicit a reply from Russell. Gödel's paper is, together with his piece on the Continuum Hypothesis [9], his most extended statement on his philosophy of logic and mathematics. In view of this disappointing lack, we have to content ourselves with a few scattered references to Gödel's work in Russell's later writings.

In an article on logical positivism published in 1945, Russell explicitly describes the Gödel incompleteness theorem as a paradox:

Carnap has shown that it is possible for a language to say things about its own syntax, but there always remain things which cannot be said in the original language, but only in the meta-language. ... The development of logical syntax on these lines, especially by Carnap, 
is very elaborate and technically difficult. Nor can it be said, as yet, to have reached a definitive form. A new set of paradoxes has been discovered by Gödel, and there can be no security that there are not others to follow [27].

In a later article on logical positivism, published in 1950, Russell describes Gödel's theorems as "puzzles" rather than paradoxes. After discussing the work of Carnap and Tarski on the liar paradox and related language hierarchies, Russell continues:

A new set of puzzles has resulted from the work of Gödel, especially his article Über formal unentscheidbare Sätze der Principia Mathematica und verwandter Systeme (1931), in which he proved that in any formal system it is possible to construct sentences of which the truth or falsehood cannot be decided within the system. Here again we are faced with the essential necessity of a hierarchy, extending upwards ad infinitum, and logically incapable of completion [29, p. 1209].

The account of Gödel's results here is certainly perfectly correct, though the use of the word "puzzle" suggests that Russell had a decided tendency to class Gödel's undecidable sentence with paradoxes such as the liar paradox and Russell's paradox, discussed earlier in his article.

The most surprising of Russell's later comments on Gödel's incompleteness theorems is in a letter to Leon Henkin of April 1 1963. Henkin had sent Russell an offprint of his prizewinning article [15] on logicism. Russell's reply contains the following passage:

Thank you very much for your letter of March 26 and for the very interesting paper which you enclosed. I have read the latter carefully and it has given me much new information. It is fifty years since I worked seriously at mathematical logic and almost the only work that I have read since that date is Gödel's. I realized, of course, that Gödel's work is of fundamental importance, but I was puzzled by it. It made me glad that I was no longer working at mathematical logic. If a given set of axioms leads to a contradiction, it is clear that at least one of the axioms must be false. Does this apply to school-boys' arithmetic, and, if so, can we believe anything that we were taught in youth? Are we to think that $2+2$ is not 4 , but 4.001 ? Obviously, this is not what is intended [14, p. 592].

Russell wrote this letter when he was 90 years old, so it is possible that these rather surprising comments can be ascribed to the effects of old age, particularly since when inviting Robin Gandy to tea on March 31, 1960 with Martin Löb and Georg Kreisel, Russell remarked: "I am completely out of touch with recent logical work and you will all have to treat me as an ignoramus" [5, p. 126]. Nevertheless, Rupert Crawshay-Williams noted in his diary:

Kreisel had said that it was astonishing how acute Russell's understanding had seemed to be even though he had not done any work 
on mathematical logic for about thirty years. It was not merely that his brain was beautifully clear for somebody of 87 ; it was beautifully clear for anybody of any age. In particular, Kreisel had told Russell about some new developments in connection with the notion of effectiveness - the one developed by Turing. Russell had clearly not been very familiar with the notion before, but he had immediately been able to follow all its complications and implications [3, pp. 129-130].

Irving Anellis reported in a posting to the FOM mailing list [1] that Russell's letter (and its "April Fool's" date) prompted Henkin to ask him during the Special Session on Proof Theory, American Mathematical Society Annual Meeting, January 5-9, 1983, in Denver, Colorado, whether Russell was joking. Anellis's opinion was that the entire tenor of the letter, together with the philosophical background on which Russell drew to conclude that Gödel's results allowed school-boy arithmeticians to have $2+2=4.001$, showed that Russell really was in earnest.

In 1973, Leon Henkin, prompted by Abraham Robinson, sent a copy of Russell's letter to Kurt Gödel. Responding to an earlier letter of Robinson, Gödel commented on Russell's remarks as follows:

Russell evidently misinterprets my result; however, he does so in a very interesting manner, which has a bearing on some of the questions we discussed a few months ago. In contradistinction Wittgenstein, in his posthumous book, advances a completely trivial and uninteresting misinterpretation [13, p. 201].

If (as I think we should) we follow Anellis in taking Russell's remarks at face value, what accounts for the misinterpretation? Russell provides us with a clue in his phrase "If a given set of axioms leads to a contradiction, it is clear that at least one of the axioms must be false." It appears that Russell was unable to free himself from the conceptual world of Principia Mathematica, where the formal development is indissolubly linked to the informal interpretation. In particular, Whitehead and Russell fail to distinguish between the concept of truth and that of provability. Recall their statement of the rule of detachment or modus ponens: "Anything implied by a true elementary proposition is true" [43, pp. 92, 94]. If we follow through this reading of Principia Mathematica, then it follows that Gödel's undecidable proposition must appear as a contradiction, in fact a form of the Liar paradox.

All of this is simply speculation, as we can only guess at what the 90year-old Russell might have had in mind. In some later comments on the incompleteness theorems, he seems to have a better grasp of the issues. In 1971 the fourth edition of The Philosophy of Bertrand Russell appeared, with an Addendum by Russell to his earlier "Replies to Criticisms." The Addendum was published posthumously, but was written at Schilpp's invitation in 1965. In it, he comments on Gödel's work as follows:

Not long after the appearance of Principia Mathematica, Gödel propounded a new difficulty. He proved that, in any systematic logical 
language, there are propositions which can be stated, but cannot be either proved or disproved. This has been taken by many (not, I think, by Gödel) as a fatal objection to mathematical logic in the form which I and others had given to it. I have never been able to adopt this view. It is maintained by those who hold this view that no systematic logical theory can be true of everything. Oddly enough, they never apply this opinion to elementary every-day arithmetic. Until they do so, I consider that they may be ignored. I had always supposed that there are propositions in mathematical logic which can be stated, but neither proved nor disproved. Two of these had a fairly prominent place in Principia Mathematica - namely, the axiom of choice and the axiom of infinity. To many mathematical logicians, however, the destructive influence of Gödel's work appears much greater than it does to me and has been thought to require a great restriction in the scope of mathematical logic. ... I adhere to the view that one should make the best set of axioms that one can think of and believe in it unless and until actual contradictions appear [33, p. xviii].

These comments appear to give a much better account of Gödel's work than the letter to Henkin. Nevertheless, there may be some remaining confusions. The remark "It is maintained by those who hold this view that no systematic logical theory can be true of everything" seems to confuse soundness and completeness (as the letter to Henkin clearly does).

In the end, it is probably impossible to interpret Russell's comments on the incompleteness theorem in a fully consistent way. His remarks combine correct summaries of Gödel's work with what appear to be quite confused and muddled ideas. Francisco Rodríguez-Consuegra gives a more charitable reading of Russell's comments; the reader is referred to his article [20] for this interpretation.

§4. The fate of Principia Mathematica. Commentators on the work of Whitehead and Russell often assert that the work of Gödel refuted the ideas of Principia Mathematica. Russell himself seems to have taken this point of view. In a letter to Alice Mary Hilton of 9 June 1963, he wrote:

The followers of Gödel had almost persuaded me that the twenty man-years spent on the Principia had been wasted and that the book had better been forgotten. It is a comfort to find that you do not take this view [32, p. 174].

In what sense, though, did Gödel's work refute that of Whitehead and Russell? If we assume that the older authors were making a claim to completeness of their system, then this is belied by their actual practice. They do not even postulate the axiom of infinity, rather leaving it as an explicit antecedent in propositions requiring it, even those of schoolboy arithmetic. As the 1971 quotation above shows, Russell was quite happy with the thought that additional postulates might be necessary in developing the foundations of mathematics. 
With over a century of hindsight, we can see that Russell was unduly defensive about the fate of Principia Mathematica. It is true that it is no longer a book that is read and studied, except by philosophers and historians of logic. But just as Sir Isaac Newton's Principia Mathematica was the foundation for mathematical physics, it was the basic work that stimulated most of the later work in mathematical logic. This is an accomplishment that should have made Russell justly proud.

This paper was presented as the retiring Presidential address at the 2016 Annual North American meeting of the Association of Symbolic Logic in Storrs, Connecticut. I would like to acknowledge the assistance of Kenneth Blackwell for help in tracing Russell's reaction to Gödel's theorem, and for calling my attention to the 1966 letter from Max Newman, as well as the passage in the book by I.A. Richards. In addition, I owe thanks to two referees whose comments improved the exposition.

\section{REFERENCES}

[1] I. Anellis, Did Gödel's result come as a surprise to Bertrand Russell? Posting to the FOM email list, March 30, 2010.

[2] A. Church, Russell's theory of identity of propositions. Philosophia Naturalis, vol. 21 (1984), pp. 513-522.

[3] R. Crawshay-Williams, Russell Remembered, Oxford University Press, London, New York, 1970.

[4] J. W. Dawson, Logical Dilemmas: The Life and Work of Kurt Gödel, A.K. Peters, Wellesley, MA, 1997.

[5] B. Feinberg and R. Kasrils (editors), Dear Bertrand Russell ... A Selection of his Correspondence with the General Public 1950-1968, George Allen and Unwin Ltd, London, 1969.

[6] G. Frege, Philosophical and Mathematical Correspondence (G. Gabriel, H. Hermes, F. Kambartel, C. Thiel, and A. Veraart, editors), University of Chicago Press, Chicago, 1980, Abridged from the German edition by Brian McGuinness and translated by Hans Kaal.

[7] K. GöDEL, Über formal unentscheidbare Sätze der Principia Mathematica und verwandter Systeme I. Monatshefte für Mathematik und Physik, vol. 38 (1931), pp. 173-198.

[8] - Russell's mathematical logic, The Philosophy of Bertrand Russell (Library of Living Philosophers Volume 5) (P. A. Schilpp, editor), Northwestern University, Evanston, 1944, pp. 123-153, [10, pp. 119-141].

[9] - What is Cantor's continuum problem? American Mathematical Monthly, vol. 54 (1947), pp. 515-525, [10, pp. 176-187].

[10] - Collected Works, Volume II: Publications 1938-1974 (S. Feferman, J. W. Dawson, Jr., S. C. Kleene, G. H. Moore, R. M. Solovay, and J. van Heijenoort, editors), Oxford University Press, New York, 1990.

[11] - Collected Works, Volume III: Unpublished Essays and Lectures (S. Feferman, J. W. Dawson, Jr., W. Goldfarb, C. Parsons, and R. M. Solovay, editors), Oxford University Press, New York, 1995.

[12] - Collected Works, Volume IV: Correspondence A-G (S. Feferman, J. W. Dawson, Jr. (Editors-in-chief), W. Goldfarb, C. Parsons, and W. Sieg, editors), Oxford University Press, New York, 2003.

[13] - Collected Works, Volume V: Correspondence H-Z (S. Feferman, J. W. Dawson, Jr. (Editors-in-chief), W. Goldfarb, C. Parsons, and W. Sieg, editors), Oxford University Press, New York, 2003.

[14] I. Grattan-Guinness, The Search for Mathematical Roots, 1870-1940: Logics, Set Theories and the Foundations of Mathematics from Cantor through Russell to Gödel, Princeton University Press, Princeton, NJ, 2000. 
[15] L. Henkin, Are logic and mathematics identical? Science, vol. 138 (1962), pp. 788-794.

[16] A. Irvine (editor), Bertrand Russell: Critical Assessments, Volume II: Logic and Mathematics, Routledge, London, New York, 1999.

[17] J. Pelham and A. Urquhart, Russellian propositions, Logic, Methodology and Philosophy of Science IX, Proceedings of the Ninth International Congress of Logic, Methodology, and Philosophy of Science, Uppsala, Sweden, August 7-14, 1991, North Holland, Amsterdam, New York, 1994, pp. 307-326.

[18] W. V. QuINE, The Time of My Life: An Autobiography, MIT Press, Cambridge, MA, 1985.

[19] I. A. Richards, Beyond, Harcourt Brace Jovanovich, New York, 1974.

[20] F. RodríGuez-Consuegra, Russell, Gödel and logicism, Philosophy of Mathematics, Proceedings of the 15th International Wittgenstein Symposium, Part 1, 1993, Reprinted in [16], pp. 320-329, pp. 233-242.

[21] B. Russell, On Denoting. Mind, vol. 14 (1905), pp. 479-493.

[22] - Les paradoxes de la logique. Revue de Métaphysique et de Morale, vol. 14 (1906), pp. 627-650.

[23] — Introduction to Mathematical Philosophy, second ed., George Allen and Unwin, London, 1920.

[24] - On order in time. Proceedings of the Cambridge Philosophical Society, vol. 32 (1936), pp. 216-228.

[25] — The Principles of Mathematics, George Allen and Unwin, London, 1937, Second Edition: First published 1903.

[26] - An Inquiry into Meaning and Truth, first ed., W.W. Norton and Company, Inc., New York, 1940.

[27] — , Logical positivism. Polemic, vol. 1 (1945), pp. 6-13, Reprinted in [35, pp. 148-155].

[28] - Whitehead and Principia Mathematica. Mind, vol. 57 (1948), pp. 137-138, Reprinted in [35, pp. 190-191].

[29] - Logical positivism. Revue internationale de philosophie, vol. 4 (1950), pp. 3-19, Reprinted in [30, pp. 323-343].

[30] - Logic and Knowledge (R. C. Marsh, editor), George Allen and Unwin, London, 1956.

[31] - The Autobiography of Bertrand Russell 1914-1944: Volume II, Little, Brown and Company, Boston, Toronto, 1968, An Atlantic Monthly Press Book.

[32] - The Autobiography of Bertrand Russell 1944-1967: Volume III, George Allen and Unwin, London, 1969.

[33] - Addendum to my 'Reply to Criticisms', The Philosophy of Bertrand Russell (P. A. Schilpp, editor), The Library of Living Philosophers, Volume V, Fourth Edition, Open Court, La Salle, IL, 1971, pp. xvii-xx.

[34] - On 'Insolubilia' and their Solution by Symbolic Logic, Essays in Analysis, by Bertrand Russell (D. Lackey, editor), George Braziller, New York, 1973, pp. 190-214.

[35] — Collected Papers Volume 11: Last Philosophical Testament 1943-1968 (J. G. Slater with the assistance of Peter Köllner, editor), Routledge, London, New York, 1997.

[36] - Collected Papers Volume 5; Toward "Principia Mathematica” 1905-1908

(G. H. Moore, editor), Routledge, London, New York, 2014.

[37] P. Arthur Schilpp (editor), The Philosophy of Bertrand Russell, Library of Living Philosophers, vol. 5, Northwestern University, Evanston, IL, 1944.

[38] A. URQuhart, Logic and denotation, Russell vs. Meinong: The legacy of "On denoting” (N. Griffin and D. Jacquette, editors), Routledge, New York, 2008.

[39] - Principia Mathematica: The first 100 years, The Palgrave Centenary Companion to Principia Mathematica (N. Griffin and B. Linsky, editors), Palgrave Macmillan, Houndmills, Basingstoke, Hampshire, 2013, pp. 3-20.

[40] H. WANG, Some facts about Kurt Gödel. The Journal of Symbolic Logic, vol. 46 (1981), pp. $653-659$.

[41] — Reflections on Kurt Gödel, The MIT Press, Cambridge, Massachusetts, 1987. 
[42] A. North Whitehead and B. Russell, Principia Mathematica, Cambridge University Press, 1910-1913, Volume 1, 1910, Volume 2, 1913, Volume 3, 1913.

[43] _ Principia Mathematica Volume 1, second ed., Cambridge University Press, Cambridge, 1927.

\author{
DEPARTMENT OF COMPUTER SCIENCE \\ UNIVERSITY OF TORONTO \\ SANDFORD FLEMING BUILDING \\ 10 KING'S COLLEGE ROAD \\ TORONTO, ON M5S 3G4, CANADA
}

E-mail: urquhart@cs.toronto.edu 